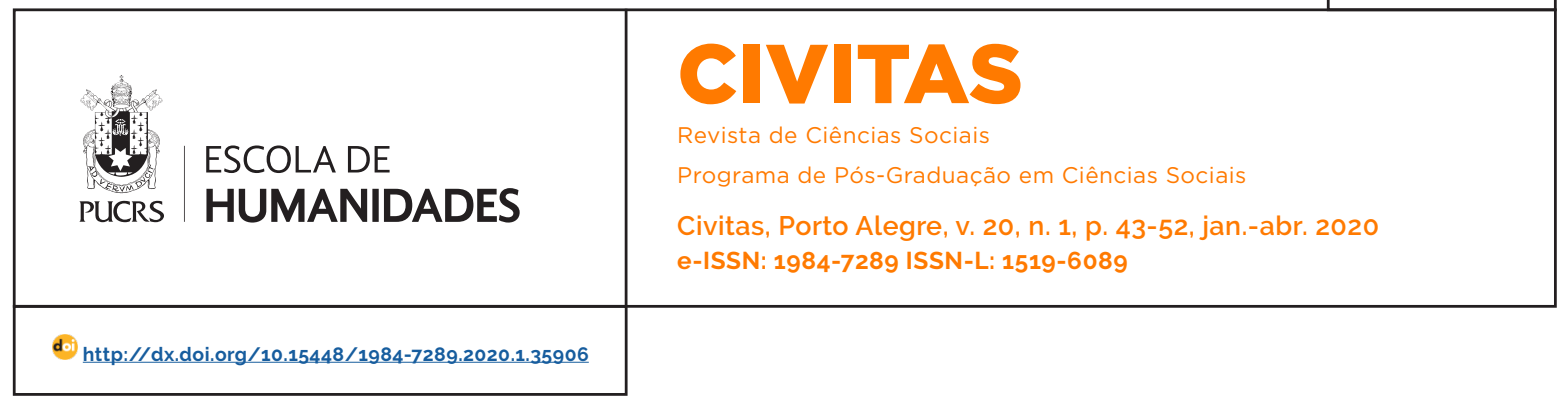

DOSSIÊ: OS NOVOS DESAFIOS DO DESENVOLVIMENTO NA REGIÃO AMAZÔNICA

\title{
Impactos da Usina Hidrelétrica de Belo Monte: uma análise da visão das populações ribeirinhas das reservas extrativistas da Terra do Meio
}

\author{
Impacts of the Belo Monte Hydroelectric Power Plant: an analysis of the perspective of \\ the riverside populations of the Terra do Meio extractive reserves \\ Impactos de la Central Hidroeléctrica de Belo Monte: un análisis desde de la \\ perspectiva de las poblaciones ribereñas de las reservas extractivas de Terra do Meio
}

\section{Maira Borges \\ Fainguelernt ${ }^{1}$}

orcid.org/0000-0002-4361-047X

mairageo@gmail.com

Recebido em: 10 jun. 2019

Aprovado em: 31 out. 2019

Publicado em: 25 mai. 2020
Resumo: Este artigo tem como objetivo discutir a área de influência dos impactos da Usina Hidrelétrica de Belo Monte, em operação desde 2016 no rio Xingu, estado do Pará. A presente discussão parte da análise da visão das populações ribeirinhas das Reservas Extrativistas da Terra do Meio dos impactos da usina para problematizar a categoria espacial que se relaciona, em particular, à exclusão dessas unidades de conservação como territórios atingidos. Utilizando métodos qualitativos que envolvem trabalhos de campo, observação participante, etnografia e entrevistas semiestruturadas, este artigo pretende destacar as contradições que envolvem o não reconhecimento das populações ribeirinhas no contexto de impactos da usina hidrelétrica de Belo Monte.

Palavras-chave: Ribeirinhos. Reservas extrativistas. Impactos. Usina hidrelétrica de Belo Monte.

Abstract: This paper aims to discuss the influence area of Belo Monte dam, in operation since 2016 in the Xingu river, state of Pará. This discussion starts with the analysis of the perspective of riverine people from extractive reserves of Terra do Meio on the impacts to problematize the spatial category that relates, in particular, to the exclusion of these protected areas as affected territories. Using qualitative methods that involve fieldwork, participant observation, ethnography, and semi-structured interviews, this paper highlight the contradictions surrounding the non-recognition of the riverine populations in the context of impacts of Belo Monte dam

Keywords: Riverine Population. Extractive reserves. Impacts. Belo Monte dam.

Resumen: Este artículo tiene como objetivo discutir el área de influencia de los impactos de la central hidroeléctrica Belo Monte, en funcionamiento desde 2016 en río Xingu, estado de Pará. La discusión actual parte del análisis de la perspectiva de la población ribereña de las reservas extractivistas de la Terra do Meio de impactos de la planta para entonces problematizar la categoría espacial que se relaciona, en particular, con la exclusión de estas áreas protegidas como territorios afectados. Usando métodos cualitativos que involucran trabajo de campo, observación participante, etnografia y entrevistas semiestructuradas, este artículo resalta las contradicciones que rodean el no reconocimiento de las poblaciones ribereñas en el contexto de los impactos de Belo Monte.

Palabras claves: Poblaciones riberenãs. Reservas extractivas. Impactos. Central Hidroeléctrica de Belo Monte. 


\section{Introdução}

Este artigo se insere no contexto de debate sobre o desenvolvimento e a conservação na região amazônica brasileira e envolve, em particular, a exclusão das Reservas Extrativistas (Resexs) da Terra do Meio de qualquer estudo prévio mais aprofundado sobre os impactos socioambientais da Usina Hidrelétrica (UHE) de Belo Monte, construída na bacia hidrográfica do rio Xingu, sudoeste do estado do Pará. Belo Monte é considerada a maior usina "100\% brasileira" e, com um orçamento 2 de cerca de 28 bilhões de reais, apresentou um processo de licenciamento ambiental polêmico. O projeto original da usina data de 1975, ainda durante a ditadura militar. quando o Brasil passou a privilegiar grandes centrais hidrelétricas a partir de um projeto desenvolvimentista, ligado a uma narrativa de necessidade de segurança energética. Após os primeiros estudos de aproveitamento hidrelétrico no rio Xingu, Belo Monte enfrentou ampla resistência social e somente foi retomada como prioridade do Governo em 2001 (Fainguelernt 2013).

Demandas por mais participação, consulta e beneficios por parte das comunidades atingidas por grandes UHEs não são novidade. Em grande parte dos casos em países em desenvolvimento, a construção de usinas é acompanhada por promessas de melhorias que não se concretizam na realidade (Moran et al. 2018). No Brasil, projetos desse porte dependem dos Estudos e Relatórios de Impactos Ambientais (EIA-Rima) para serem licenciados, processo que define as áreas de influência e cria a categoria de "atingidos", que acarreta tanto em processos de inclusão, como de exclusão, ocasionando diversos desafios socioambientais:

The priority in large dam construction is to generate energy to serve growing industries and urban populations - these two things often overwhelm socioeconomic and environmental considerations (13). Left behind are local communities saddled with socioenvironmental damages and loss of livelihoods (14). Often, they do not even gain access to electricity, because they are not provided the power from the large dams, and they are not sufficiently compensated for their disrupted lives. (Moran et al. 2018)

Este trabalho ${ }^{3}$ tem como objetivo discutir a influência dos impactos de Belo Monte a partir da análise da visão das populações ribeirinhas das três da Terra do Meio - Resex do Iriri, Resex do Xingu e Resex do Riozinho do Anfrísio. A área de estudo apresenta uma dinâmica territorial complexa que envolve dez Áreas Protegidas (APs): cinco Unidades de Conservação (UCs) federais - Resex do Xingu, do Iriri e do Riozinho do Anfrisio, Parque Nacional da Serra do Pardo e Estação Ecológica da Terra do Meio; duas UCs estaduais - APA Triunfo do Xingu e FES do Iriri; e três Terras Indigenas (TIS) - TI Cachoeira Seca, TI Xipaya e TI Kuruaia. As Resexs 4 são consideradas UCs de uso sustentável, definidas legalmente na Lei n. 9.985, de 18 de julho de 2000 que instituiu o Sistema Nacional de Unidades de Conservação da Natureza (SNUC). São territórios onde populações extrativistas podem permanecer no interior e a cultura e o modo de vida devem ser protegidos a fim de compatibilizar a conservação da natureza com o uso sustentável dos recursos naturais. As Resexs são territórios habitados pelas populações ribeirinhas, descendentes de processos de miscigenação entre povos europeus, indígenas e africanos (Pace 1997: Nugent 1993) e a história dos ribeirinhos da Terra do Meio se relaciona diretamente com os ciclos econômicos da borracha na região amazônica (Almeida 1993). Muito já foi debatido sobre a invisibilidade dessas populações que ainda se encontram marginalizadas da sociedade (Adams e Neves. 2006) e, em particular, o histórico das populações no Xingu foi marcado por conflitos de terra, invasões e grilagem que ainda hoje ameaçam a manutenção do modo de vida

\footnotetext{
2 Belo Monte representa um dos maiores financiamentos na história do Banco Nacional de Desenvolvimento Econômico e Social (BNDES), já que o banco arcou com cerca de $80 \%$ do custo.

3 Este artigo é um desdobramento da tese de doutorado da autora, defendida em 19 de março de 2019 no Programa de doutorado em Ambiente e Sociedade, Universidade de Campinas.

4 Ver definição legal de Resex na lei n. 9.985, de 18 de julho de 2000 que institui o Sistema Nacional de Unidades de Conservação da Natureza - SNUC.
} 
tradicional (Velásquez, Villas Boas e Schwartzman 2006), dos direitos territoriais e da biodiversidade.

\section{Metodologia}

Esta pesquisa qualitativa se nutriu no arcabouço da tese de doutorado da presente autora junto ao Programa de Pós-Graduação em Ambiente e Sociedade, da Universidade de Campinas, e envolveu um debate teórico entre a geografia e a antropologia com o objetivo de avançar no entendimento das interações homem-ambiente na Amazônia, a partir de um olhar voltado à territorialidade ribeirinha. As principais fontes primárias foram documentos oficiais do processo de licenciamento ambiental da UHE, como pareceres técnicos dos órgãos responsáveis pela avaliação dos impactos do empreendimento. A pesquisa documental e a realização das entrevistas semiestruturadas (Bernard 2011) com os ribeirinhos e atores locais foram realizadas durante duas pesquisas de campo (2016 e 2017).

A análise da visão ribeirinha foi realizada a partir do primeiro trabalho de campo do doutorado 5 (2016) que viabilizou a realização de 60 entrevistas semiestruturadas com ribeirinhos das três Resexs corrobora tal afirmação o depoimento do ribeirinho entrevistado na Terra do Meio que destacou diferentes dimensões dos impactos de Belo Monte: "Impacto não é igual a alagamento. Pra gente, o impacto começou no preço, não temos mais condição de comprar nada. Em Altamira, hoje em dia, temos medo de morrer quando andamos e a população aumentou muito" (Entrevistado A, 25 de março de 2016).

O EIA-Rima da área de aproveitamento hidrelétrico de Belo Monte foi elaborado em 2009 pela empresa Leme Engenharia (Fearnside 2006). ${ }^{6}$ Esse é o documento que define as áreas de influência dos impactos, portanto, além de elencar os territórios e as populações atingidas, estabelece as condicionantes das licenças ambientais - que acompanharão o processo de licenciamento ambiental - e as consequentes medidas de mitigação e de compensação ambiental. Tais medidas devem ser cumpridas pela empresa responsável, nesse caso, a Norte Energia (Nesa).

Desta forma, a partir de estudos de impactos nos meios físico, biótico, socioeconômico e cultural, o EIA-Rima delimita a abrangência espacial dos impactos de Belo Monte que se resume em quatro grandes áreas: (1) área diretamente afetada (ADA) - delimitada pelos reservatórios e obras, ou seja, área relativa à própria construção ${ }^{7}$ da usina; (2) a área de influência direta (AID) da UHE que corresponde aos diferentes compartimentos ligados à construção, às áreas vizinhas a Altamira e, já com objetivo de abarcar impactos socioeconômicos, inclui cinco municípios - Altamira, Vitória do Xingu, Senador José Porfírio, Anapu e Brasil Novo; (3) a área de influência indireta (All) de Belo Monte, que inclui outros municípios que fazem parte de região de integração do Xingu, Medicilândia, Uruará, Placas, Porto de Moz, Gurupá e Pacajá; e (4) por último, a área de abrangência regional (AAR) dos impactos, que é a mais distante da Volta Grande do Xingu e engloba toda a bacia hidrográfica do rio Xingu (ver figura 1).

Figura 1 - Área de influência da UHE Belo Monte.

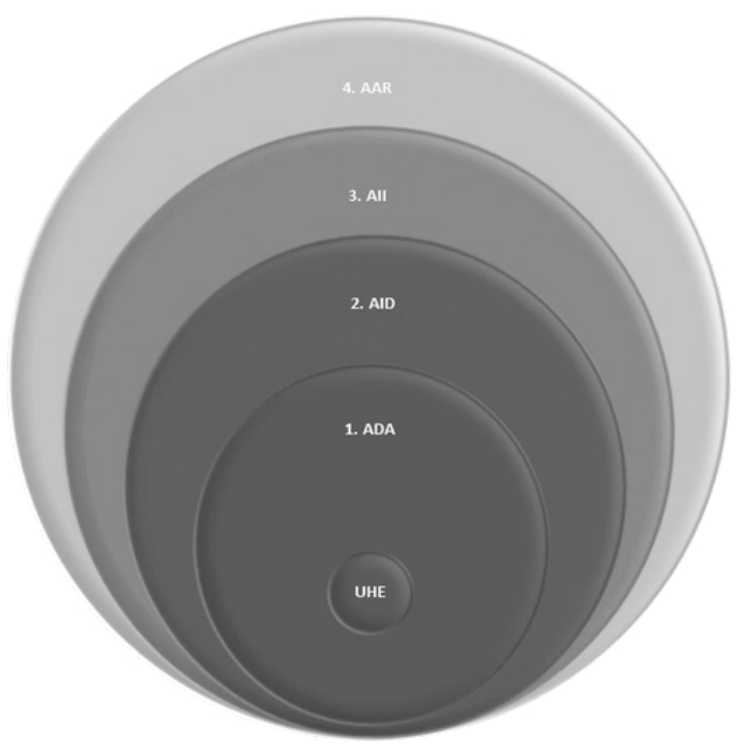

5 O primeiro trabalho de campo teve início no dia 16 de fevereiro de 2016 e término no dia 31 de março. Foram quarenta e cinco dias, sendo que doze dias na cidade de Altamira e os outros trinta e três dias nas Resexs da Terra do Meio.

6 A Leme Engenharia mudou de nome e agora chama-se Tractbel Engie, ver mais informações em: https://tractebel-engie.com.br/pt.

Sítios Pimental, Bela Vista, Belo Monte e região dos canais e diques. 
Fonte: Diagrama elaborado pela autora com dados do Rima (2009) de Belo Monte.

A Terra do Meio integra a AAR de Belo Monte e somente duas APs do mosaico foram consideradas no EIA-Rima da usina desde o princípio: TI Cachoeira Seca e ESEC da Terra do Meio. Destaca-se que a cidade de Altamira, próxima à barragem principal de Belo Monte na Volta Grande do Xingu, faz parte da ADA e todas as APs da Terra do Meio estariam, assim, fora da área de impacto direto ou indireto de Belo Monte delimitada no EIA-Rima.

Neste contexto em que o atingido é considerado a partir de uma lógica de distância, cabe destacar a "dupla moradia" (grande parte dos ribeirinhos desta região mantém uma casa na cidade e uma casa na ilha ou na UC), parte fundamental ao modo de vida ribeirinha, que não foi considerada na delimitação da abrangência espacial dos impactos de Belo Monte, nem na posterior elaboração de medidas de mitigação e compensação ambiental. A territorialidade dessas comunidades é marcada pela íntima relação entre o meio rural e o urbano, o que mistura distintas lógicas no complexo e sazonal modo de vida ribeirinho. ${ }^{8}$ No caso das comunidades das Resexs, muitos moradores mantêm uma casa de apoio na cidade de Altamira, seja própria ou coletiva (das associações de moradores das Resexs), o que possibilita aos ribeirinhos da Terra do Meio saírem do isolamento territorial das UCS e alcançarem os centros urbanos próximos, onde têm acesso à diversos serviços públicos, benefícios sociais e mercadorias.

\section{A visão das populações ribeirinhas da Terra do Meio dos impactos de Belo Monte}

Cabe destacar os três grandes temas que, apesar de entrelaçados, nortearam a análise inicial de dados primários da presente pesquisa: (a) dimensão ecológica - visão ligada a impactos específicos na fauna e na flora, um olhar que destaca impactos de Belo Monte nos recursos naturais - principalmente a pesca e a caça e também na água do rio (qualidade ou nível); (b) dimensão social - visão que associa a UHE ao aumento da violência, da prostituição e da criminalidade na cidade de Altamira, além da noção de desestruturação de laços afetivos após a remoção compulsória de familiares e amigos que moravam no "beiradão" de Altamira (e foram removidos para reassentamentos urbanos coletivos - RUCs - sem acesso ao rio):9 e (c) dimensão econômica - visão relacionada à diminuição do poder de compra das famílias ribeirinhas, consequência do aumento do custo de mercadorias na cidade de Altamira, fundamentais por complementarem o modo de vida nas Resexs. ${ }^{10}$

Para a análise da visão dos ribeirinhos entrevistados no segundo campo, além dos três grandes temas elencados acima, outras duas dimensões foram recorrentes nas entrevistas: (d) dimensão cultural - visão que compara a visibilidade e/ou reconhecimento de direitos entre populações indígenas e ribeirinhas na Terra do Meio; e (e) dimensão política - que aponta relações de poder entre diferentes stakeholders no mosaico e destaca que após a construção da usina, houve aumento do número de invasões de pescadores de fora das APs, o que ressalta uma noção associada ao controle territorial. Desta forma, cinco grandes dimensões interconectadas foram evidenciadas na análise da visão dos ribeirinhos dos impactos de Belo Monte. Destaca-se um depoimento que expressa tal entrelaçamento na visão dos ribeirinhos entrevistados sobre os impactos de Belo Monte:

Chegava em Altamira e era uma tranquilidade só, hoje não temos nem onde encostar o barco, antes chegávamos e sabiamos para onde ir. Hoje

\footnotetext{
8 Em uma linguagem oriunda da geografia humana, a territorialidade pode ser melhor entendida como uma estratégia e um comportamento espacial para controlar, usar e influenciar pessoas, coisas e recursos (Sack 1986). Portanto, sob essa perspectiva esta noção encontra-se intimamente relacionada à forma como as pessoas usam a terra e como organizam sua vida espacialmente.

9 Poucos moradores das Resexs que tinham casa na região que será alagada em Altamira, chamada de ADA, aceitaram a opção de serem indenizados e afirmaram durante as entrevistas que o valor que a empresa ofereceu não viabilizava a compra de nada em Altamira. Dessa forma, aceitavam - sem alternativa real - a casa construida em um dos RUCs.

10 As mercadorias nas Resexs também chegam por regatões que comercializam produtos que complementam as necessidades dos moradores das UCs da Terra do Meio há muitos anos.
} 
em dia não sabemos mais onde os conhecidos estão morando. Hoje em dia não tem ninguém pra atender com um serviço, como consertar um motor. Pra comprar ficou difícil, os preços aumentaram demais depois de Belo Monte. Antigamente, não existiam tantos pescadores e depois da barragem, aumentou muito. O povo do Riozinho do Anfrisio, por exemplo, nem pescava. Os hospitais estão muito cheios na cidade e eu nunca tinha visto uma seca assim tão grande. A Norte Energia trouxe mais violência, fico até com medo de sair à noite na cidade. Muitos pais aqui da Resex ficam sofrendo por causa dos filhos que podem "se perder" na cidade. (Entrevistado B, 01 de março de 2016)

Sobre a dimensão ecológica, impactos futuros nas Resexs, na moção n. ${ }^{\circ} 01$ de 18 de outubro de 2015, o conselho deliberativo da Resex do Xingu chamou atenção para o receio dos moradores em relação ao aumento do nivel da água do rio, a consequente perda de ambientes marginais, como igapó e mata ciliar, o alagamento dos "baixões" e a perda de seringais, e as possiveis mudanças na territorialização tanto dos peixes como dos animais caçados habitualmente. Perspectivas ligadas a aspectos ecológicos relacionam-se às atividades de pesca e ao rio: "O peixe também diminuiu. A mudança foi tão grande que os peixes tão todos ovados e nessa época não era para ter, pois já passou o tempo deles se reproduzirem (janeiro na cheia)" (Entrevistado C, 14 de junho de 2017).

Pescadores entrevistados apontaram para a diferença no tamanho do peixe e cabe destacar que é um recurso móvel que exige acompanhamento contínuo para documentar alterações: "Para a gente aqui (na Resex) foi prejuízo, existem várias áreas que peixe sobe e desce, depende da época do ano. Está dando é muito peixe pequeno" (Entrevistado D, 22 de fevereiro de 2016).

Na Resex do Iriri, os impactos na pesca foram mais evidentes do que nas outras Resexs, sendo que é a UC que conta com maior número de moradores que dependem dessa atividade econômica:

Eu comecei a pescar aos 10 anos, eu nunca tinha visto o que vi esse ano, eu pego pescada magrinha com espinha junta. Muitos viram isso, não fui só eu não e eu fiquei pensando muito na barragem, porque a mudança foi do ano passado pra cá. Fidalgo, pescada e tucunaré estão todos doentes e os peixes não conseguem desovar, estão todos ovados, tucunaré desova direto, curimatá é agora. (Entrevistado E, 05 de março de 2016)

No entanto, não há consenso entre os moradores das Resexs sobre um impacto direto da construção da barragem nos recursos pesqueiros. Um fator que contribui para a existência de certa controvérsia a esse respeito é o fato de o periodo da construção da barragem ter coincidido com um periodo de uma forte seca na região. Muitos ribeirinhos afirmaram ter ocorrido um fenômeno climático bem semelhante há cerca de trinta anos, o que poderia influenciar a perspectiva de parte dos entrevistados quanto à diminuição do recurso pesqueiro, já que tem ligação direta às condições ecológicas, como por exemplo, ausência de certos frutos que os peixes se alimentam em específicos pontos de pesca na Resex.

A coincidência entre a existência de uma forte seca e o início das obras de Belo Monte gerou controvérsias dentro das comunidades a respeito da diminuição do recurso pesqueiro, já que, a partir das entrevistas, tornou-se evidente que moradores da mesma Resex sentem tais aspectos ecológicos de forma bem diferente. Moradores do Iriri afirmaram que tal redução do recurso pode também ter relação com o aumento do número de pescadores de fora da Resex, pois o aumento das vendas em Altamira no periodo da construção da usina estimulou a pesca na região. Muitos deles, afirmam que - por conta disso - está ocorrendo a diminuição dos recursos pesqueiros.

\footnotetext{
Antigamente, peixe era em bando, podia pescar com isca de pano vermelho que pescava muito. Tem muito peixe miúdo. De três anos pra cá começou a diminuir a pesca. Estava entrando pescador de fora da Resex pelo Maribel, continuam entrando e botando espinhel. Mês passado eu vi, tem muito pescador entrando ali. (Entrevistado F, o6 de março de 2016).
}

Diversos depoimentos também revelaram que existe uma preocupação dos moradores com a sustentabilidade dos recursos pesqueiros, ou seja, com as próximas gerações:

Eu pesco Tucunaré e Pescada para vender e sinto que o peixe diminuiu nos últimos anos. 
Hoje temos que mariscar (pescar) seis ou sete dias para conseguir a quantidade de peixe que antes conseguiamos em apenas dois ou três. (Entrevistado G, 23 de fevereiro de 2016)

Além da dimensão ecológica, a dimensão social foi recorrente nos depoimentos e se relaciona especificamente à Altamira, localizada na ADA. O que motiva o ribeirinho da Resex ir à cidade se conecta à diferentes aspectos: (i) resolução de problemas de saúde, marcação de exames e necessidades de cirurgias e atendimentos de emergências em hospitais; (ii) compra de roupas e calçados para a família; (iii) resolução de questões de documentação; e (iv) retirada de pagamento de benefícios sociais. Muitos ribeirinhos afirmaram que o atendimento a serviços ficou muito prejudicado após a construção d Belo Monte:

O atendimento à saúde está mais dificil. Sesp era mais próximo, agora emergência é na UPA, só que hospital que interna as pessoas é lá no mutirão, não sei nem onde é direito. A Nesa dizia que ia fazer dois hospitais e nada aconteceu. Só fizeram um e não deu nem pra metade da população. (Entrevistado H, 27 de fevereiro de 2016)

A frequência de ida à cidade do ribeirinho dos Resexs varia bastante e de acordo com necessidades, mas, normalmente, são duas ou três vezes ao ano e, na maioria dos casos, o deslocamento é realizado via barco ou voadeira, com a articulação de caronas com familiares e amigos. Muitos entrevistados relataram, de maneira enfática, a dificuldade de manter contato com parentes e amigos que, após a construção da UHE, foram removidos da "beirada" da cidade de Altamira e agora estão nos chamados RUCs:11 "Minhas irmãs agora estão no Jatobá. Ficava em Altamira na casa delas. Nunca mais fui depois que elas se mudaram pro RUC, então parei de ir visitar, porque é sacrifício demais" (Entrevistado I, 08 de março de 2016).

Os RUCs são o resultado das negociações realizadas na ADA. A Nesa removeu mais de 22 mil pessoas das margens do rio Xingu em Altamira e hoje existem seis novos bairros localizados na periferia da cidade construidos pela empresa. A remoção compulsória na ADA, segundo relato dos entrevistados, teve impacto direto nas relações sociais dos ribeirinhos das Resexs, já que acarretou em um processo de desestruturação de laços com impacto direto na territorialidade e no modo de vida dessas populações: "Minha mãe foi enrolada, a casa está rachada, não tem segurança. Era antigamente uma casa boa na beira do rio, fica muito longe e quase não vejo mais" (Entrevistado J, 8 de março de 2016).

Diversas familias do Riozinho do Anfrísio e do Iriri relataram a importância do acesso à cidade de Altamira via Transiriri e Transamazônica, já que durante o verão (período da seca), muitas vezes, é impossivel o deslocamento pelo rio Xingu de barco, sendo a TI Cachoeira Seca fundamental para o deslocamento dos moradores das APs da Terra do Meio.

Associada diretamente à cidade de Altamira também está a dimensão econômica dos impactos de Belo Monte que, especificamente, os ribeirinhos apontaram a perda do poder de compra após a construção da UHE:

\begin{abstract}
O custo de roupa, comida e aluguel de casa aumentou muito na cidade. Os hospitais do estado estão lotados. Atualmente, pra ver minha família tenho que pagar 100 reais de táxi ida e volta mais 20 reais para olharem o barco. Nunca mais vi meu irmão, já tem um ano. Nem sei mais onde ele mora. Antigamente eu chamava o meu pai do rio. Com a vinda da Nesa perdemos concorrência também. Arroz farinha e peixe tão chegando de fora. Tem supermercado vendendo peixe barato que vem de fora e ninguém quer mais o daqui. Os barcos não têm mais onde encostar em Altamira, agora temos que ficar no meio do rio. Pescadores de Altamira já estão começando a subir para a reserva trazendo malhadeira e tudo mais. (Entrevistado L, 03 de março de 2016)
\end{abstract}

Pescadores entrevistados também destacaram mudanças que ocorreram na cadeia produtiva do pescado oriundo das Resexs após a construção da Usina de Belo Monte, no entanto, alguns não acreditam que isso tenha afetado as reservas: "Atualmente, tem vindo muito peixe de fora para Altamira, tambaqui que vem de

11 Todos os RUCS foram visitados no primeiro trabalho de campo e a estrutura de todos é basicamente a mesma (escola, mercado, unidade básica de saúde etc.), com exceção dos RUCs Laranjeiras e Pedral, que têm acesso ao Igarapé. 
Santarém, por exemplo, mas ainda não diminuiu a venda aqui na reserva não".

Um dos atravessadores entrevistados em Altamira em 2017 corrobora tal visão quando afirma:

Se você perguntar pro ribeirinho que peixe que ele come, vai ser pacu, curimatã, matrinchã e arituia. Nisso não tem muita diferença, porque esses são os peixes que não tem mercado aqui mesmo. 0 pacu até tinha, mas o tambaqui tomou conta em Altamira. Porque o pacu "rimpeia" (endurece), o tambaqui (de tanque) vem do Mato Grosso e do Maranhão e chega aqui mais barato, então vende mais. (Entrevistado M, 10 de março de 2016)

Por outro lado, um dos atravessadores mais importantes da região que trabalhou muitos anos com ribeirinhos no Iriri afirmou:

Em 2013 e 2014 vendia muito peixe aqui, mas tinha muito peixe que vinha até do Vietnã e São Paulo. Esse do Vietnã (ou talvez da Indonésia) é um peixe industrializado e sem sabor, hoje não venderia mais nenhum. Não foi tão bom pra vender peixe das Resex com a barragem, porque o povo que veio de fora não tem conhecimento de peixe, então vinha panga, merluza ou caraaçu e se bota pra vender, eles vão comer do mesmo jeito, porque é peixe, eles não sabem a diferença. Por isso que hoje também tá indo pirara e trairão pra fora da nossa região aqui, porque aqui não vendia esse. Com a barragem baixou a venda dos peixes deles e aumentou o custo das mercadorias e do óleo diesel. Agora melhorou um pouco já essa coisa do preço. Hoje em dia tava com um pescador só no Iriri, porque a logística é muito cara, 3 mil reais o frete complica muito. (Entrevistado N, 10 de março de 2016)

A partir do acompanhamento do desembarque pesqueiro no Porto de Maribel (localizado na TI Cachoeira Seca), foi possivel observar tais mudanças, já que parte significativa do pescado das Resexs, atualmente, segue para um frigoríico chamado "Peixão", em Santarém, via um novo atravessador que atua na Terra do Meio. Ainda, contando com o depoimento do atravessador da região:

O peixe que Adriano leva não tem procura aqui na nossa região e ai vai tudo pra Santarém, depois pra Goiânia e depois pro Sudeste, até São Paulo chega o peixe do Iriri. Santarém é mais perto e como o peixe tem que ir pra um frigorifico pra sair com nota, vai pra lá. (Entrevistado O. 24 de fevereiro de 2016)
Atualmente, esse atravessador não trabalha mais com os regatões e pescadores do Iriri, pois foi contratado pela Norte Energia - via empresa DB Cavalli - que hoje é responsável por assessorar a cadeia produtiva de peixe nas TIs da região, para cumprir as medidas exigidas pelo Plano Básico Ambiental (PBA) de Componente Indígena ( $\mathrm{Cl}$ ).

Tem dez anos que trabalho com as comunidades lá do Iriri. Agora tô fazendo o projeto da Norte Energia, na verdade a DB Cavalli pega e eu faço a logistica. É uma logistica cara que tem que ter investimento, né? Antes os indios da Cachoeira Seca não pescavam. Pra eles, foi o melhor negócio que já deu. Hoje estamos trabalhando com cinco aldeias. Eu nunca puxei peixe, só comprava peixe. Hoje toda a semana eu pago 8 mil, oito mil e pouco pra esses indios (pago 8 reais o $\mathrm{Kg}$ ). Não sei quanto que a DB Cavalli recebe da Norte Energia, ai é com eles. Mas sei que eles dão pros indios gasolina, gelo, isopor e a DB Cavalli me paga o frete. O gasto dos indios é zero, não tá sendo um mal negócio pra eles não. (Entrevistado P, 24 de fevereiro de 2016)

Sobre a dimensão política, dois atores-chave locais foram destacados - o órgão gestor Instituto de Conservação da Biodiversidade (ICMBio) e a organização não governamental (ONG) Instituto Socioambiental (ISA) - responsáveis por diversos projetos importantes na região. Os ribeirinhos entrevistados expressaram certa insatisfação - e até omissão - com a atuação tanto do órgão governamental como em relação ao reconhecimento de impactos de Belo Monte nas Resexs: "Não sei por que o ICMBio e o ISA disseram que não seríamos impactados" (Entrevistado Q, 15 de junho de 2017.

Um desses atores - que trabalha diretamente com os ribeirinhos na Terra do Meio desde 2009 - destacou a atuação dos stakeholders e a relação intensa dos ribeirinhos das Resexs com a cidade de Altamira:

As lideranças dizem que o ICMBio não tomou pé da situação como a Funai e acabaram os deixando fora das compensações de Belo Monte. Infelizmente, minha vivência mostra que os impactos da usina chegam a mais de $400 \mathrm{~km}$ de distância. A relação com a cidade sempre existiu, a maioria dos moradores não tinha casa na cidade e sempre ficavam hospedados nos parentes que viviam na beira de Altamira. Hoje 
em dia essas pessoas estão nos bairros novos criados pela Nesa e os ribeirinhos da Resex ficam em barcos no meio do rio. Não tem mais porto, não tem energia, não tem segurança. Eles não têm condição de pagar táxi nem vigia. (Entrevistado R, 2 de março de 2016)

A dimensão cultural da visão dos ribeirinhos é notável e está articulada à dimensão política, já que expressa a relação de poder existente entre diferentes populações e comunidades tradicionais e a capacidade de articulação de atores locais, conforme demonstra o seguinte depoimento: "Os índios já têm aquele poder com a Funai que corre atrás das coisas. Nós não temos também cacique, ficamos esperando alguém do ICMBio ou do ISA para ajudar.

Tal dimensão étnica está ligada diretamente às medidas de mitigação da UHE que são visíveis aos olhos dos ribeirinhos do Iriri quando chegam na TI Cachoeira Seca. Para cumprir o Plano Básico Ambiental (PBA) de Componente Indígena ( $\mathrm{Cl}$ ), exigido pela Funai, a Nesa contratou uma outra empresa chamada DB Cavalli para comprar o pescado das populações indigenas da Cachoeira Seca, consideradas diretamente atingidas pela usina.

Na cidade está difícil vender o peixe. Antes da barragem era mais fácil. Pão lum dos atravessadores de Altamira) hoje em dia está só comigo há 1 ano. Antes ele comprava peixe do Manuel etc. O Adauto (outro atravessador de Altamira) também ficou só com o Manin (regatão e ribeirinho). Há um ano atrás, ele comprava muito mais peixe, acho que 5 ou 10 pescadores, hoje só de um só. (Entrevistado S, 28 de fevereiro de 2016)

Os Araras da TI Cachoeira Seca - território vizinho à Resex do Iriri - por exemplo, com as medidas de mitigação de Belo Monte receberam, além de novas voadeiras e gasolina, material para pescar, gelo e caminhão para transportar o pescado até cidades próximas. Em relação ao tratamento que a Nesa deu aos indígenas vizinhos, a maioria dos ribeirinhos entrevistados ressaltou a diferença de reconhecimento de direitos e consequentes benefícios na Terra do Meio. Apesar de existir uma relação de amizade entre ribeirinhos e indigenas, o que permite que se ajudem, por exemplo, em momentos de emergências de saúde, e também com compra e venda de farinha e peixe, os depoimentos foram carregados de comparações entre os dois territórios vizinhos - TI e Resex:

O cacique Raoni desde sempre brigou contra a barragem e nós não fizemos nada na época que deveriamos, não sabiamos nem assinar o nome nem o que era uma associação direito. Indigenas tinham quem brigasse por eles. Tem lei que protege o ribeirinho, mas nós não sabemos disso, não tínhamos o conhecimento para brigar e sermos reconhecidos no PBA. (Entrevistado S. 20 de março de 2016)

Foi a partir do segundo campo de pesquisa que foi possivel aprofundar a análise da visão dos ribeirinhos da região. A quantidade e a variedade de impactos sociais negativos notados pelos entrevistados reforçam a forte relação dos moradores das Resexs com a cidade de Altamira. A fragmentação e/ou ruptura de relações sociais e afetivas após a construção da usina, que também apontam para uma maior dificuldade no acesso a serviços e mercadorias na cidade, pode ser ressaltada como um dos principais impactos de Belo Monte. Cabe destacar que é dentro dessa escala que se situa a dimensão social e econômica da visão dos ribeirinhos dos impactos negativos da usina em Altamira. A degradação da qualidade de vida é relacionada, principalmente, ao serviço de saúde na cidade (mais filas, mais tempo esperando para ser atendido e localização do hospital mais longe do "beiradão") e o aumento da violência na cidade, muitos deles afirmam terem mais medo pelo aumento da criminalidade ${ }^{12}$ na cidade de Altamira após a construção de Belo Monte. "A cidade de Altamira mudou muito, muita bandidagem, nem sentimos vontade de ir. Não tem casa de parente pra ficar".

Neste sentido, para os ribeirinhos do Iriri, os impactos da UHE ocorreram, principalmente, em duas escalas geográficas que estão intimamente articuladas à dinâmica territorial da Terra do Meio e ao complexo modo de vida de seus 
habitantes. Uma escala envolve a visão ribeirinha que sinaliza mudanças dentro da Terra do Meio - considerada AAR - e a outra envolve mais diretamente as mudanças sociais e econômicas associadas à cidade de Altamira - concebida como ADA e AID. Assim, a visão dos ribeirinhos na Terra do Meio está associada às dimensões política, ecológica e cultural do território, com destaque para a questão étnica, que envolve a comparação com as populações indigenas vizinhas. Já em Altamira, os impactos ressaltados pelos ribeirinhos do Iriri têm relação direta com os aspectos socioeconômicos, tendo destaque. em particular, a perda do poder de compra em Altamira e a ruptura de significativos laços sociais.

\section{Considerações finais}

Grandes projetos de infraestrutura devem ser acompanhados de estudos que analisem e monitorem suas consequências, que deveriam trabalhar por melhorias na qualidade de vida e na noção de bem-estar dos indivíduos, grupos e comunidades atingidas (Vanclay 2013 citado em Barrow 2010). A construção de Belo Monte no rio Xingu repetiu erros de outras UHEs na Amazônia - como Tucuruí no rio Tocantins - e reproduziu controvérsias e conflitos já enfrentados por populações atingidas por outros grandes projetos de infraestrutura na região amazônica (Fearnside 2005). Em estudos prévios à construção de grandes barragens, os benefícios socioeconômicos continuam sendo sobrestimados e os custos ambientais subdimensionados (Moran et al. 2018).

As experiências vividas e relatadas pelos ribeirinhos das Resexs indicam que os impactos da usina foram sentidos e percebidos de diferentes formas e em múltiplas escalas, diretamente relacionadas à territorialidade e ao modo de vida dessas populações que conectam as distintas áreas de influência da UHE para além de distâncias concretas em relação à área alagada. Os impactos relatados na cidade de Altamira expressam como a questão da distância física é relativa quando se trata de impactos de UHEs na Amazônia.
Sem considerar a territorialidade ribeirinha, não há como avaliar, de maneira apropriada, os impactos de grandes barragens. Essas populações apresentam outras lógicas, articulam diversas escalas geográficas de forma particular e sazonal e possuem um modo de vida baseado em um sistema complexo de atividades com dinâmicas intimamente ligadas ao rio, à floresta e à cidade.

A pesquisa destacou também que, dentre as dimensões do território/territorialidade, a dimensão cultural - que se relaciona ao espaço vivido, ao sentimento de pertencimento, à identidade e, também, à subjetividade dos grupos sociais - foi subdimensionada no contexto de estudo dos impactos de Belo Monte, fato que dificulta a visibilidade das populações ribeirinhas neste contexto de construção de grandes projetos de infraestrutura na região amazônica. Apesar de em 2015, as Resexs terem sido incluidas na AAR dos impactos da usina, foram consideradas, oficialmente, apenas na condicionante 2.24 da Licença de Operação (LO) de Belo Monte 1317/2015, que indicou que a Nesa, apesar de não estar de acordo que exista uma relação direta entre a construção de Belo Monte e a diminuição dos recursos pesqueiros nas Resexs, deveria desenvolver um projeto chamado Assistência à Pesca Sustentável nessas UCS. A possibilidade de serem ainda "beneficiários" do prometido progresso e desenvolvimento, ao mesmo tempo que é um discurso que seduz as populações locais, em muitos casos, também as desqualifica do direito de atuar como agentes políticos, ou seja, sujeitos com voz e direito de participação ao longo do processo de decisão e negociação. Por fim, em um contexto de impactos de grandes UHEs na Amazônia, a presente reflexão contribui para a visibilidade dos ribeirinhos e pretende estimular estudos, soluções, medidas de mitigação, compensação e políticas públicas mais coerentes com a realidade destas populações.

\section{Referências}


Adams, Cristina, Rui Murrieta e Walter Neves. 2006 Sociedades caboclas amazônicas: modernidade e invisibilidade. São Paulo: Fapesp, Annablume.

Almeida, Mauro William Barbosa de. 1993. Rubber tappers of the upper Jurua river, Brazil: the making of a forest peasant economy. Social anthropology doctoral thesis, University of Cambridge, Cambridge. https:// doi.org/10.17863/CAM.16267.

Barrow, Christopher J. 2010. How is environmental conflict addressed by SIA? Environmental Impact Assessment Review 30, n5: 293-301. https://doi.org/10.1016/j.eiar.2010.04.001.

Bernard, Harvey Russell. 2011. Research methods in anthropology: qualitative and quantitative approaches. Lanham: Altamira Press.

Campbell, John L., Quincy Charles, Osserman Jordan and Ove K. Pedersen. 2013. Coding in-depth semistructured interviews: problems of unitization and intercoder reliability and agreement. Sociological Methods \& Research 42, no 3: 294-320. https://doi. org/10.1177\%2F0049124113500475.

Fainguelernt, Maira. B. 2013. Belo Monte: o estado democrático de direito em questão. Rio de Janeiro: Apicuri.

Fearnside, Philip M. 2006. Dams in the Amazon: Belo Monte and Brazil's hydroelectric development of the Xingu river basin. Environmental Management 38, $\mathrm{n}^{\circ}$ 1: 16-27. https://doi.org/10.1007/s00267-005-0113-6.

Moran, Emilio Federico, M. C Lopez, N. Moore, N. Muller, and D. W. Hyndman. 2018. Sustainable hydropower in the 21st century. Proc Natl Acad Sci (PNAS) 115, n 47: 11891-11898. https://doi.org/10.1073/pnas.1809426115.

Nugent, S. 1993. Amazonian Caboclo Society: an essay on invisibility and peasant economy. Providence, Oxford: Berg Publishers. https://doi.org/10.1016/0261-3050(95)900551.

Pace, Richard. 1997. The Amazon Caboclo: What's in a name? Luso-Brazilian Review 34, n²: 81-89. Acessado em jun., 2018. https://WwW.jstor.org/stable/3514152.

Vainer, Carlos Bernando. 2008. O conceito de "atingido": uma revisão do debate e diretrizes. In Vidas alagadas. Conflitos socioambientais, licenciamento e barragens, organizado por Franklin Daniel Rothman, 39-63. Viçosa: Editora UFV.

Vanclay, Frank, James T. Baines and Nicholas Taylor. 2013. Principles for ethical research involving humans: ethical professional practice in impact assessment Part I. Journal Impact Assessment and Project Appraisal 31, $n^{\circ} 4$ : 243-253. https://doi.org/10.1080/14615517.2013.850307.

Velasquez, Cristina, André Villas Boas e Stephen Schwartzman. 2006. Desafio para a gestão ambiental integrada em território de fronteira agrícola no oeste do Pará. Revista de Administração Pública 40, n 6: 1061-1075. http://dx.doi.org/10.1590/So03476122006000600007.

Sack, Robert David. 1986. Human territoriality: its theory and history. Cambridge: Cambridge University Press. https://doi.org/10.1086/ahr/94.1.103.

\section{Maíra Borges Fainguelernt}

Doutora em Ambiente e Sociedade pela Universidade Estadual de Campinas (Unicamp), Campinas, SP, Brasil, pós-doutora por Michigan State University (MSU, East Lansing, MI, Estados Unidos), pesquisadora integrante do projeto de pesquisa Rethinking dams: innovative hydropower solutions to achieve sustainable food and energy production and sustainable communities. 